\title{
Ethylene/Higher $\alpha$-Olefin Copolymerization Behavior of Fluorinated Bis(phenoxy-imine)titanium Complexes with Methylalumoxane: Synthesis of New Polyethylene-Based Block Copolymers
}

Rieko Furuyama, Makoto Mitani, Jun-ichi Mohri, Ryoji Mori, Hidetsugu Tanaka, Terunori Fujita*

R\&D Center, Mitsui Chemicals, Inc., 580-32 Nagaura, Sodegaura, Chiba 299-0265, Japan

Terunori.Fujita@mitsui-chem.co.jp

Supporting Information

1. Preparation of complex 2.

2. DFT calculation results of cationic active species.

3. ${ }^{1} \mathrm{H}$ NMR spectra of the poly(ethylene-co-higher $\alpha$-olefin)s produced by complex 4/MAO.

4. ${ }^{13} \mathrm{C}$ NMR spectrum of the poly(ethylene-co-1-hexene) produced by complex 4/MAO.

5. GPC profiles of the poly(ethylene-co-higher $\alpha$-olefin)s produced by complex 4/MAO.

6. DSC curves for the PE-b-poly(ethylene-co-1-hexene)s formed with complex 4/MAO. 


\section{Preparation of complex 2 .}

Complex 2 was synthesized using a similar method reported ${ }^{1}$. 2-Cyclohexylphenol was obtained from Honshu Chemical Industry Co., Ltd.

3-cyclohexylsalicylaldehyde: a pale yellow oil, $78 \%$ yield. ${ }^{1} \mathrm{H}$ NMR $\left(\mathrm{CDCl}_{3}\right) \delta 1.21-1.90$ (m, 10H, cyclohexyl-H), 3.01 (s, 1H, cyclohexyl-CH), 6.90-7.49 (m, 3H, aromatic-H), 9.88 (s, 1H, CHO), $11.36(\mathrm{~s}, 1 \mathrm{H}, \mathrm{OH})$.

$N$-(3-cyclohexylsalicylidene)-2,3,4,5,6-pentafluoroaniline: yellow crystals, $80 \%$ yield. ${ }^{1} \mathrm{H}$ NMR $\left(\mathrm{CDCl}_{3}\right) \delta 1.25-1.94(\mathrm{~m}, 10 \mathrm{H}$, cyclohexyl-H), 3.11 (s, 1H, cyclohexyl-CH), 6.91-7.41 (m, $3 \mathrm{H}$, aromatic-H), $8.81(\mathrm{~s}, 1 \mathrm{H}, \mathrm{CH}=\mathrm{N}), 12.56(\mathrm{~s}, 1 \mathrm{H}, \mathrm{OH})$.

Bis[N-(3-cyclohexylsalicylidene)-2,3,4,5,6-pentafluoroanilinato]titanium(IV)dichloride (2): reddish brown crystals, 33\% yield. ${ }^{1} \mathrm{H}$ NMR $\left(\mathrm{CDCl}_{3}\right) \delta 1.25-1.94(\mathrm{~m}, 22 \mathrm{H}$, cyclohexyl-CH), 7.05 (d, $J=7.6 \mathrm{~Hz}, 2 \mathrm{H}$, aromatic-H), 7.29 (dd, $J=7.8,1.6 \mathrm{~Hz}, 2 \mathrm{H}$, aromatic-H), 7.47 (dd, $J=7.6,1.6 \mathrm{~Hz}, 2 \mathrm{H}$, aromatic-H), $8.28(\mathrm{~s}, 2 \mathrm{H}, \mathrm{CH}=\mathrm{N})$; FD-MS, 854 $\left(\mathrm{M}^{+}\right)$. Anal. Found; $\mathrm{C}, 53.12 ; \mathrm{H}, 3.44 ; \mathrm{N}, 3.16$. Calcd. for $\mathrm{TiC}_{38} \mathrm{H}_{30} \mathrm{~N}_{2} \mathrm{O}_{2} \mathrm{~F}_{10} \mathrm{Cl}_{2}: \mathrm{C}, 53.36 ; \mathrm{H}$, $3.53 ; \mathrm{N}, 3.27$. 


\section{DFT calculation results of cationic active species.}

All calculations were performed at the gradient-corrected density functional BLYP level by means of the Amsterdam Density Functional Program (ADF 2003. 01). ${ }^{2}$ All geometries were optimized using a triple $\zeta$ STO basis set for the titanium atom $(3 \mathrm{~s}, 3 \mathrm{p}, 3 \mathrm{~d}, 4 \mathrm{~s}, 4 \mathrm{p})$ and a double $\zeta$ STO basis sets for the carbon $(2 \mathrm{~s}, 2 \mathrm{p})$, nitrogen $(2 \mathrm{~s}, 2 \mathrm{p})$, oxygen $(2 \mathrm{~s}, 2 \mathrm{p})$ and hydrogen (1s) atoms. The inner shells except for hydrogen atoms were treated within the frozen core approximation. For the calculations of Mulliken charges, the triple $\zeta$ STO basis set on the titanium and the double $\zeta$ plus polarization STO basis sets on the other atoms were used and the quasi relativistic correction was also added at the optimized geometries. The classical electrostatic energies between the $\beta$-hydrogen of an ${ }^{n}$ propyl group and the nearest neighboring fluorine were estimated by the following equation:

$\mathrm{ES}=\rho\left(\mathrm{H}_{\beta}\right) \rho(\mathrm{F}) / \mathrm{r}\left(\mathrm{H}_{\beta}-\mathrm{F}\right)$

Here $\rho\left(\mathrm{H}_{\beta}\right)$ and $\rho(\mathrm{F})$ stand for Mulliken charges of the $\beta$-hydrogen and the nearest neighboring fluorine, respectively, and $\mathrm{r}\left(\mathrm{H}_{\beta}-\mathrm{F}\right)$ is the distance between those two atoms in Angstroms. All units are in atomic unit $\left(=1.60 \times 10^{-19}\right.$ Coulombs).

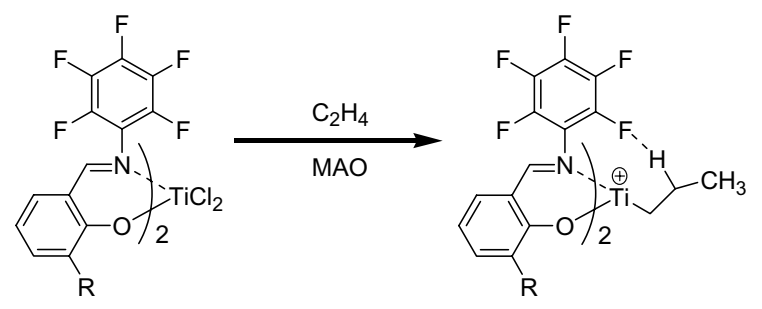

\begin{tabular}{ccccc}
\hline complex & $\mathrm{r}^{a}\left(\mathrm{H}_{\beta}-\mathrm{F}_{\mathrm{o}}\right)$ & $\rho^{b}\left(\mathrm{H}_{\beta}\right)$ & $\rho^{b}\left(\mathrm{~F}_{\mathrm{o}}\right)$ & $\mathrm{ES}^{c}\left(\mathrm{H}_{\beta}-\mathrm{F}_{\mathrm{o}}\right)$ \\
\hline $\mathbf{1}$ & 2.328 & 0.09 & -0.46 & -24.8 \\
$\mathbf{2}$ & 2.515 & 0.10 & -0.46 & -25.1 \\
$\mathbf{3}$ & 2.311 & 0.09 & -0.46 & -26.3 \\
$\mathbf{4}$ & 2.260 & 0.09 & -0.46 & -25.5 \\
$\mathbf{5}$ & 2.302 & 0.08 & -0.46 & -23.2 \\
\hline
\end{tabular}

${ }^{a}$ Atomic distance $(\mathrm{r})$ in $\AA{ }^{\circ}{ }^{b}$ Mulliken charge $(\rho)$ in atomic unit $\left(=1.60 \times 10^{-19}\right.$ Coulombs $) .{ }^{c}$ Electrostatic Energy (ES) in $\mathrm{kJ} \mathrm{mol}^{-1}$. 
3. ${ }^{1}$ H NMR spectra of the poly(ethylene-co-higher $\alpha$-olefin)s produced by complex 4/MAO.

(1) Ethylene/1-hexene copolymer (1-hexene $17.7 \mathrm{~mol} \%$ )

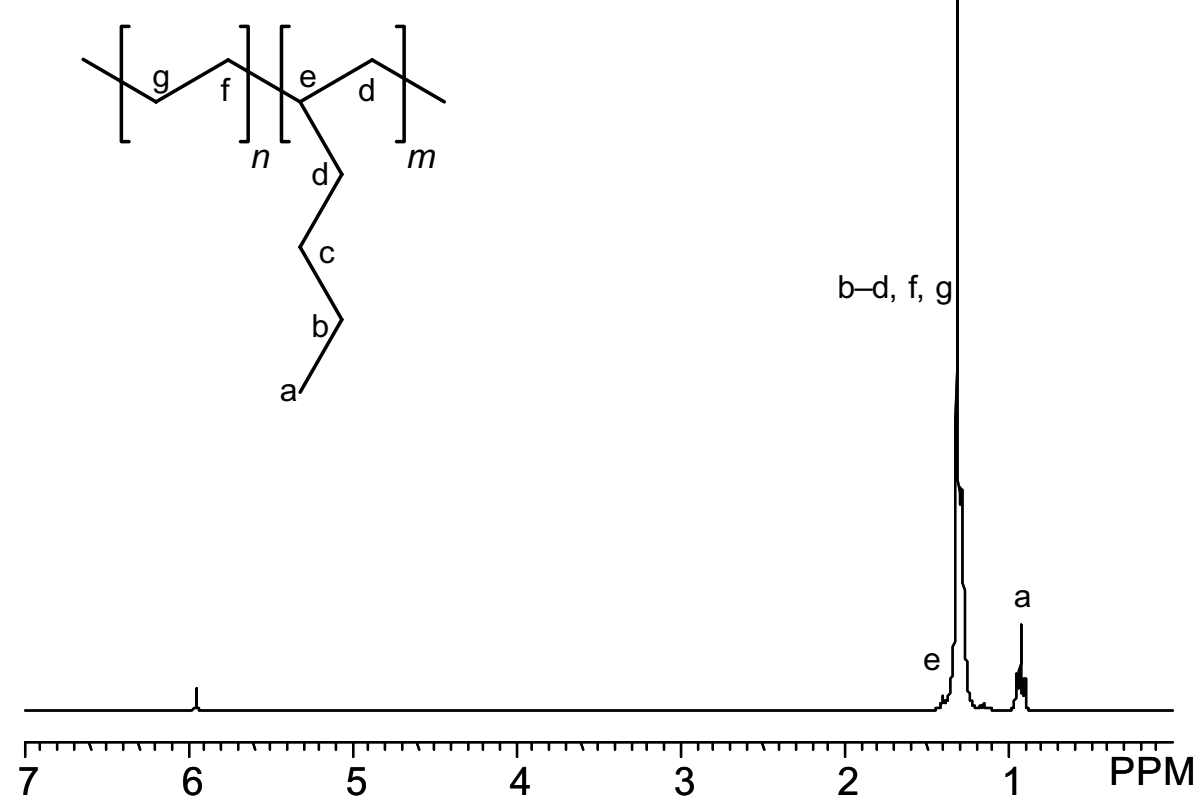

(2) Ethylene/1-octene copolymer (1-octene $12.6 \mathrm{~mol} \%$ )

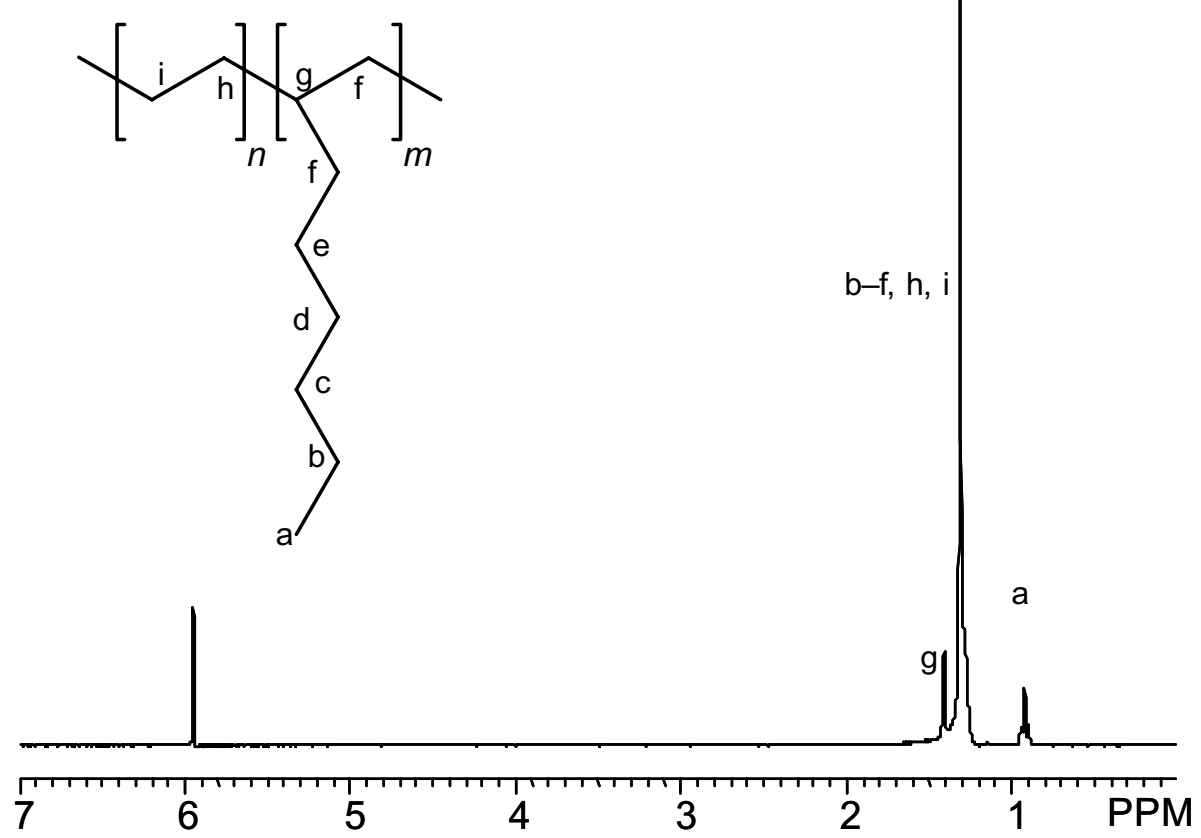


(3) Ethylene/1-decene copolymer (1-decene $11.3 \mathrm{~mol} \%$ )

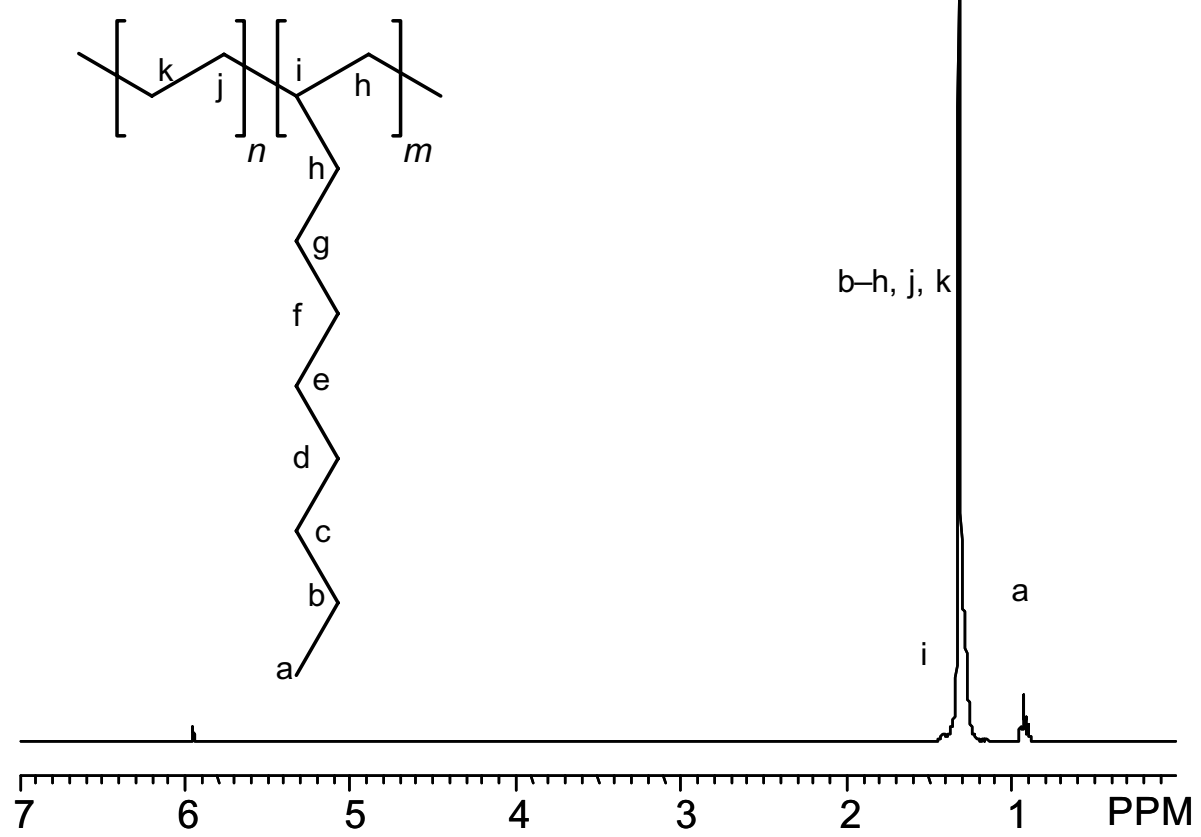

4. ${ }^{13} \mathrm{C}$ NMR spectrum of the poly(ethylene-co-1-hexene) produced by complex 4/MAO (1-hexene $17.7 \mathrm{~mol} \%$ ).

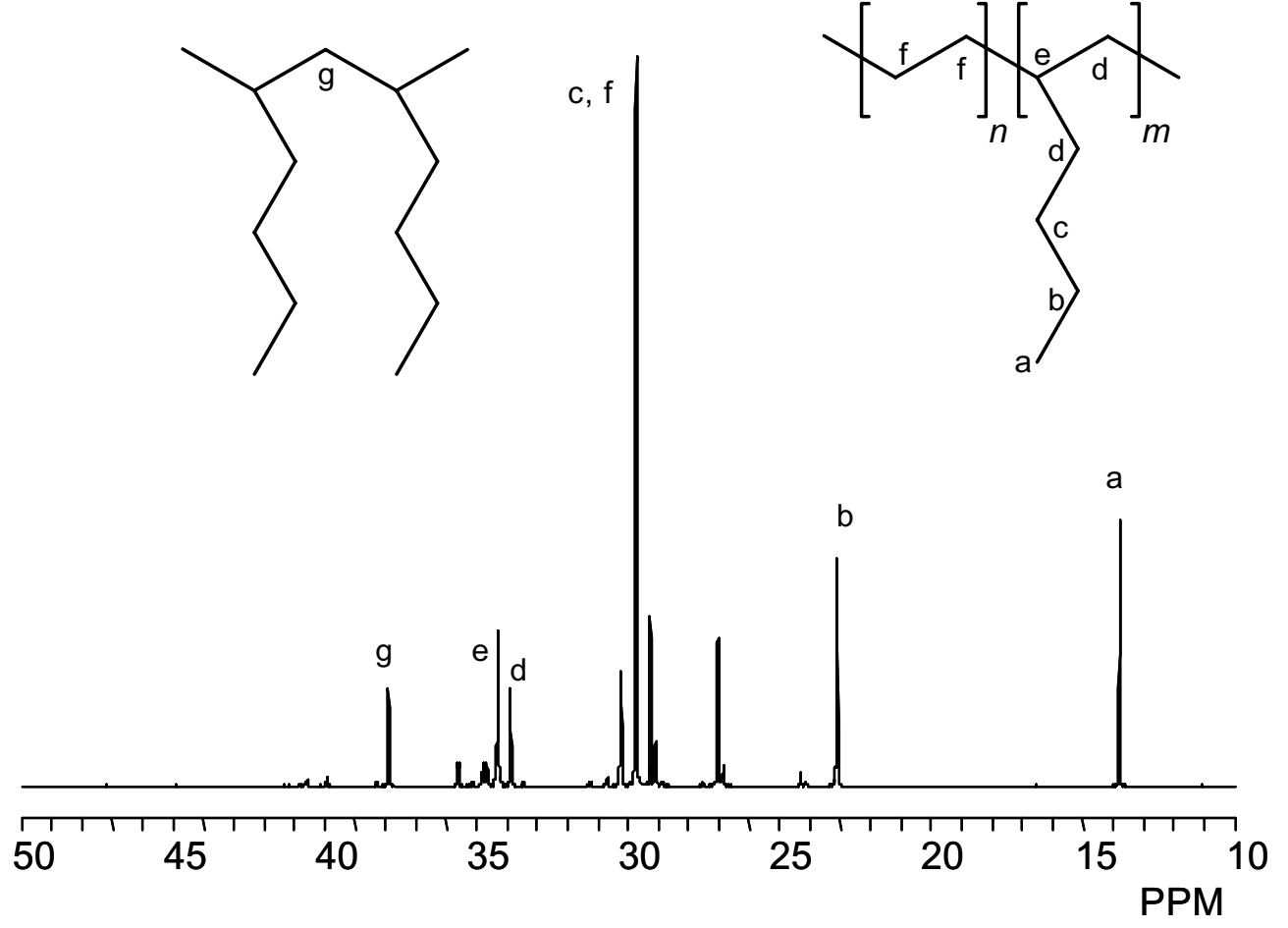


5. GPC profiles of the poly(ethylene-co-higher $\alpha$-olefin)s produced by complex 4/MAO.

(1) Ethylene/1-hexene copolymer $\left(M_{\mathrm{n}}{ }^{a} 102000, M_{\mathrm{w}} / M_{\mathrm{n}}{ }^{a} 1.12,1\right.$-hexene $\left.{ }^{b} 17.7 \mathrm{~mol} \%\right)$

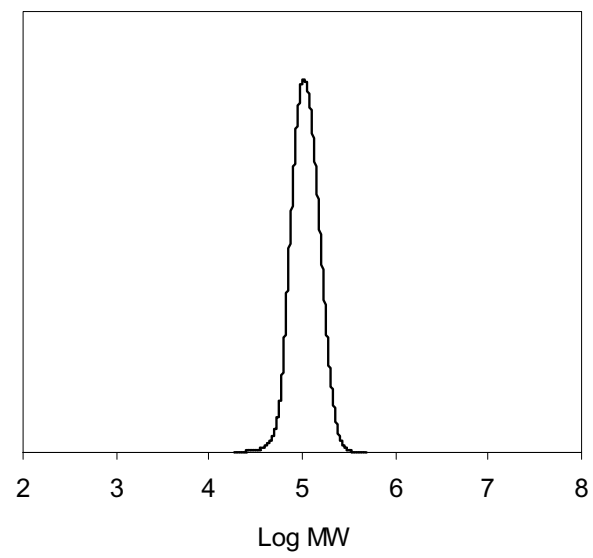

(2) Ethylene/1-octene copolymer $\left(M_{\mathrm{n}}{ }^{a} 110000, M_{\mathrm{w}} / M_{\mathrm{n}}{ }^{a} 1.15,1\right.$-octene $\left.{ }^{b} 12.6 \mathrm{~mol} \%\right)$

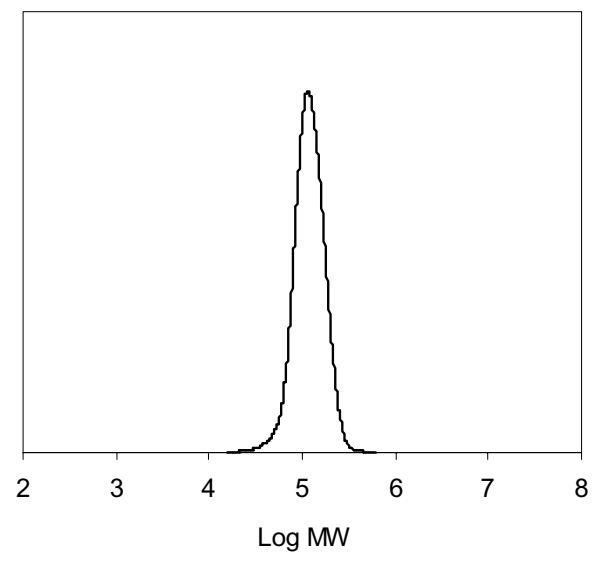

(3) Ethylene/1-decene copolymer $\left(M_{\mathrm{n}}{ }^{a} 128000, M_{\mathrm{w}} / M_{\mathrm{n}}{ }^{a} 1.16,1\right.$-decene $\left.{ }^{b} 11.3 \mathrm{~mol} \%\right)$

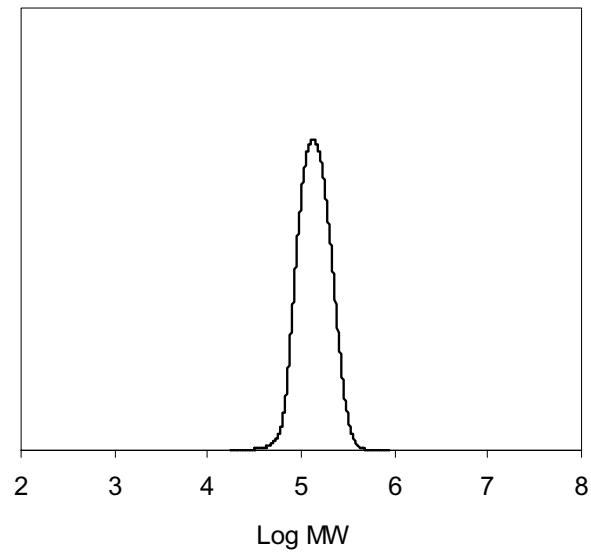

${ }^{a}$ Determined by GPC using polyethylene calibration. ${ }^{b}$ Higher $\alpha$-olefin content of block copolymer (determined by ${ }^{1} \mathrm{H}$ NMR). 
6. DSC curves for the PE-b-poly(ethylene-co-1-hexene)s formed with complex 4/MAO.

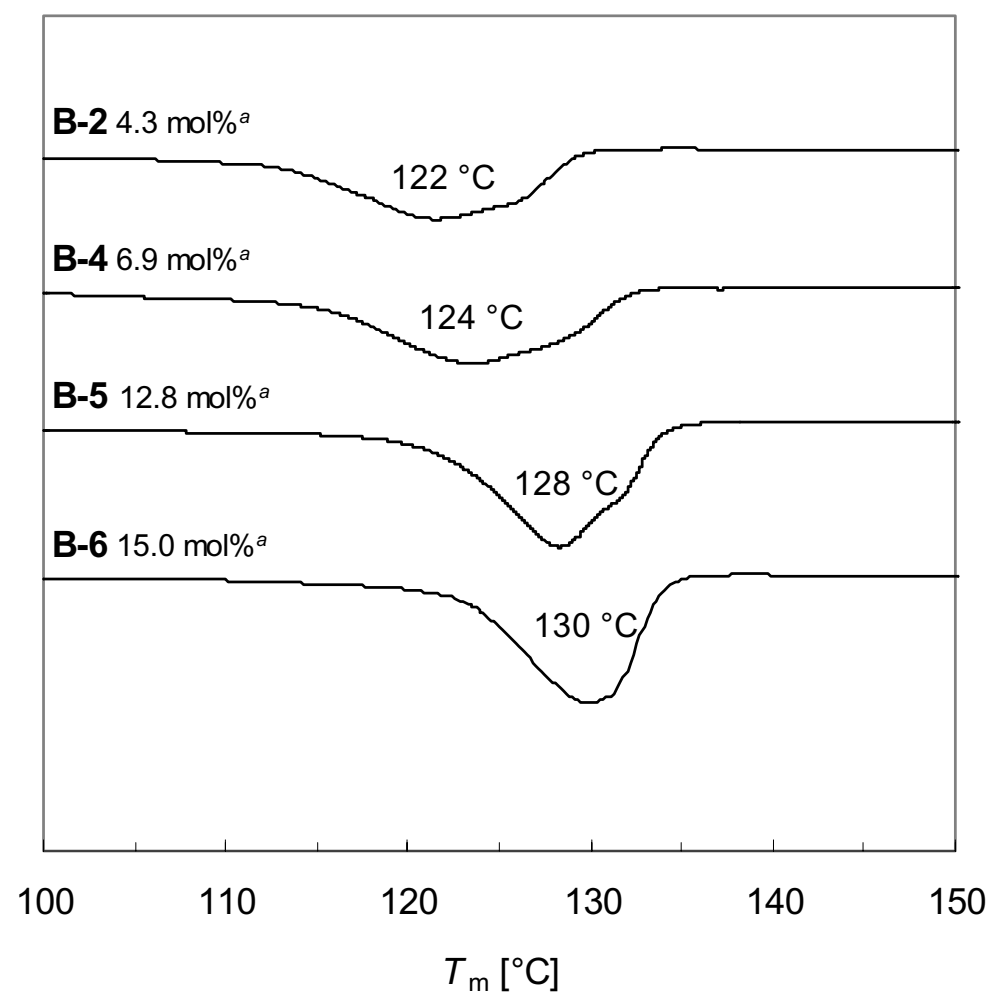

${ }^{a} 1$-Hexene content of the block copolymer (Determined by ${ }^{1} \mathrm{H}$ NMR). 
References and Notes

(1) Mitani, M.; Furuyama, R.; Mohri, J.; Saito, J.; Ishii, S.; Terao, H.; Nakano, T.; Tanaka, H.; Fujita, T. J. Am. Chem. Soc. 2003, 125, 4293-4305.

(2) (a) te Velde, G.; Bickelhaupt, F. M.; van Gisbergen, S. J. A.; Fonseca Guerra, C.; Baerends, E. J.; Snijders, J. G.; Ziegler, T. J. Comput. Chem. 2001, 22, 931-967. (b) Fonseca Guerra, C.; Snijders, J. G.; te Velde, G.; Baerends, E. J. Theor. Chem. Acc. 1998, 99, 391-403. (c) ADF2003.01, SCM, Theoretical Chemistory, Vrije Universiteit, Amsterdam, The Netherlands, http://www.scm.com. 